\title{
O BIODIREITO E A POLUIÇÃO INVISÍVEL: INTRODUÇÃO À COMPLEXIDADE
}

\section{THE BIOLAW AND INVISIBLE POLLUTION: INTRODUCTION TO COMPLEXITY}

\author{
${ }^{1}$ Isabele Bruna Barbieri \\ ${ }^{2}$ Paulo Roney Ávila Fagúndez
}

\section{RESUMO}

A presente pesquisa tem por escopo a análise e reflexão sobre a importância do pensamento complexo para avaliar as diversas formas de poluição invisível, a fim de que o biodireito e a bioética atuem para melhor regulamentar os direitos humanos fundamentais, à vida, à saúde, à dignidade do homem e das demais formas de vida. Este estudo propõe introduzir a complexidade como novo paradigma, novo olhar, instrumento essencial para a sociedade de risco imersa nas mais diversas incertezas científicas. Para alcançar tal objetivo, o presente trabalho busca trazer os pressupostos teóricos, investigando o problema a partir da revisão bibliográfica.

Palavras-chave: Biodireito, Saúde, Vida, Poluição, Complexidade

\begin{abstract}
This research aims to achieve the analysis and reflection on the importance of complex thinking to evaluate the various forms of invisible pollution, so that the biolaw and bioethics act to better regulate the fundamental human rights to life, health, dignity of man and of other forms of life. This study proposes to introduce complexity as a new paradigm, new look, essential tool for risk society that has the most diverse scientific uncertainties. To achieve this goal, this paper seeks to bring the theoretical assumptions, investigating the problem from the literature review.
\end{abstract}

Keywords: Biolaw, Healf, Life, Pollution, Complexity

\footnotetext{
${ }^{1}$ Mestrado em andamento em Direito Universidade Federal de Santa Catarina - UFSC, Florianópolis - SC (Brasil). E-mail: isabele@ibbadvocacia.adv.br

${ }^{2}$ Doutor em Direito pela Universidade Federal de Santa Catarina - UFSC, Florianópolis - SC (Brasil). Professor da Universidade Federal de Santa Catarina - UFSC, Florianópolis - SC (Brasil)

E-mail: roney@pge.sc.gov.br
} 


\section{CONSIDERAÇÕES INICIAIS: BIODIRIETO E O CONTEXTO ATUAL}

O contexto da sociedade pós-moderna está inserida nos mais diversos cenários sombrios. O cenário ambiental revela a complexidade das questões a que a sociedade está implantada, a atenção para os problemas ambientais descortinou o cenário de risco, a poluição e suas danosas consequências para o homem e para o planeta.

Também, o social embutido nas antigas desigualdades sociais, cujo discurso do capitalismo e do desenvolvimento não cumpriram com o seu papel, restando ainda os excluídos em situação de mais privações econômicas, habitacionais e de poluição ambiental.

Além destas realidades distorcidas do meio ambiente e da sociedade, ainda tem-se uma grande mudança no conhecimento científico, onde o homem, que antes era sujeito, passou a ser objeto também, sendo apropriado pela dinâmica tecnocientífica, que tem como características a voracidade objetivante e capitalizante. (RIOS, 1999)

A problemática reside na realidade da biotecnologia, da biomedicina, do biodireito com as mais avançadas pesquisas sobre o ser humano, sobre químicos e inovações tecnológicas e a aplicações dessas soluções tecnológicas, fazem surgir conflitos jurídicos até então, desconhecidos pelo legislador, o que reclama a elaboração de normas jurídicas para solucionar as situações de modo a proteger a vida.

O presente artigo, por meio da revisão bibliográfica, propõe-se a analisar e refletir sobre a importância e essencialidade do pensamento complexo, especialmente acerca da poluição invisível, a fim de que o biodireito e a bioética possam regulamentar as atividades e atitudes humanas sob o viés da proteção dos direitos humanos, proteção da vida, da saúde, do meio ambiente e da dignidade dos homens e das demais formas de vida.

Como se abordará, a visão sistêmica e complexa é o novo paradigma, todavia, o que se percebe são soluções compartimentadas e que não priorizam a dignidade da vida humana e das demais formas de vida.

Vislumbra-se no horizonte uma policrise (MORIN, 1995) que é uma série de crises, econômica, social, jurídica, ambiental, familiar, de valores que permeiam e moldam as bases da estrutura da civilização atual, uma crise ampla que atinge os diversos setores da sociedade e da vida no planeta.

Um espetáculo ainda mais sombrio e pior, é que aliado a esta policrise há uma crise de percepção (CAPRA, 1982) da realidade a que está inserida a sociedade, no sentido de ser irracional imaginar a possibilidade de permanência do sistema desenvolvimentista nos níveis 
de atuação da sociedade industrial hodierna com a capacidade planetária, a qual não comportará a continuação do modo de vida atual da sociedade.

Esta crise de percepção narrada por Capra (CAPRA, 1982) enuncia que a visão mecanicista da ciência é uma visão obsoleta para a realidade atual, que não pode mais ser observada em função dos conceitos deste modelo. O novo paradigma deve conter uma visão sistêmica, holística da realidade, isso porque o mundo de hoje vive imerso em uma realidade interligada, onde os fenômenos biológicos, psicológicos, sociais e ambientais são todos interdependentes.

Desta forma, o movimento de se pensar a respeito dos riscos ambientais e do uso correto das novas tecnologias demandam a superação de paradigmas arraigados na sociedade, como a superação da visão patrimonialista do Direito, do neoliberalismo, o hiperconsumo, a mercantilização da vida e demais movimentos prejudiciais ao homem e a sobrevivência do Planeta Terra.

A busca constante pelo desenvolvimento sustentável e novas formas de respeito a vida, sugere aos pesquisadores a necessidade de superação do individualismo e da racionalidade para uma perspectiva coletiva, planetária e participativa.

O desenvolvimento sustentável e o debate acerca da problemática ambiental trouxe a necessidade do novo, sendo que este novo não tem valor específico, mas sim caráter geral, que significa o novo pensamento, o novo sentir, a nova ética, uma nova perspectiva desgarrada do racionalismo para dar lugar a transformação social e das pessoas para uma sociedade solidária.

Todavia, esse dito novo é um processo lento, mas que deve ser contínuo, visto que mesmo com décadas de debates acerca da essencialidade da nova consciência voltada para a proteção ambiental, ainda percebe-se arraigado valores mesquinhos e estritamente econômicos.

Mas do que isso, além da mercantilização de todos os recursos naturais e também dos animais não-humanos, há também, com as novas descobertas da ciência e da biologia, a mercantilização do próprio homem. A ciência se desfez do objetivo originário de busca para alcançar uma melhor qualidade de vida, e vestiu-se sob o manto da economia de mercado, preocupada com a produção de produtos a serem vendidos.

Por isso, acredita-se que é esta presença exacerbada de valores economicistas e refletida de modo geral no pensamento de um desenvolvimento padronizado capitalista da 
sociedade, que continua justificando a permanência dos interesses econômicos não apenas sobre a natureza, mas também, e violentamente, sobre o próprio semelhante, o ser humano.

Logo, da mesma forma, esta característica reflete também nos direitos atuais, visto que apesar das diversas discussões acerca da proteção do meio ambiente e do surgimento de novos direitos do homem, a sociedade ainda não conseguiu sopesar o poder econômico e a dignidade da pessoa humana.

Mais do que isso, importante abandonar a visão salvadora da ciência, que tudo provê, que tudo transforma e que tudo melhora. Muito pelo contrário, a ciência não tem mais capacidade de prever os riscos e as incertezas, não pode garantir que suas soluções tecnológicas permitirão a continuidade da vida no planeta, e mais, uma vida digna.

Por isso, a reversão deste quadro caótico não se dará por meio da razão divina, mágica ou milagres tecnológicos, isso porque nesta crise sistêmica a ciência isoladamente não tem conseguido descobrir a solução para os problemas. Pelo contrário, seu efeito tem contribuído para alienação dos indivíduos no sentido de pregar a tecnologia como a salvadora que irá descobrir e produzir meios de se superar o recurso consumido, poluído e esgotado ou a saúde prejudicada. Para ao fim, a medicina chegando ao extremo de acreditar e buscar a imortalidade do homem.

Neste diapasão, insere-se também as questões do direito, dos avanços tecnológicos, da ética conectados à medicina, à biotecnologia, à dignidade da pessoa humana. A atual relação dos homens com a vida demanda uma reflexão sistêmica, na qual a bioética e o biodireito desempenham papel fundamental. Para tanto, é o questionamento desse presente artigo, no sentido de dimensionar a importância do pensamento complexo nas decisões acerca do biodireito e, mais especificamente, a saúde humana atrelada a poluição invisível.

Não se pretende esgotar o tema da complexidade aliada ao biodireito e a bioética, mas introduzir a argumentação da análise da poluição invisível na perda da dignidade do homem e a necessidade do biodireito considerar essa fonte de poluição para adentrar a uma possível solução.

A solução, em parte, reside no fato de ser necessária a elaboração normativa para superação de conflitos concretos, em contextos variados, incorporando a visão da complexidade no debate do biodireito.

Adentrar no ramo da bioética é relembrar os seus principais princípios, da autonomia, da beneficência, da não maleficência, da justiça e o da dignidade da pessoa humana, essenciais para uma conduta ética perante a vida. 
Desta forma, para que haja respeito a vida e a dignidade da pessoa humana é necessário refletir sobre os impactos que as atividades humanas tem produzido, principalmente aqueles de difícil constatação mas que influenciam negativamente o meio ambiente e na saúde coletiva.

\section{A POLUIÇÃO INVISÍVEL E A SAÚDE HUMANA}

Além dos poluentes já conhecidos e de fácil constatação perceptíveis pelo mau cheiro, coloração e outras características, existe ainda uma preocupação com aqueles praticamente invisíveis e de difícil constatação. A poluição invisível, como é o caso da poluição eletromagnética, dos agrotóxicos nas águas, solo e ar, hormônios e antibióticos presentes nos produtos industrializados e tantos outros, estão espalhadas no cotidiano das pessoas e ninguém as vê.

O panorama atual acerca das novas poluições invisíveis e seus impactos pode ser comparado ao cenário descrito no livro 'A poluição Invisível' (BOUGUERRA, 1997) que discorre acerca do posicionamento da comunidade científica, das instituições e da sociedade sobre os pesticidas, radiações, agentes químicos, naquela época considerados inofensivos.

No ano de 1983 se desconhecia os efeitos nocivos da dioxina e os efeitos de muitos pesticidas. Naquela época os pesticidas eram a promessa de um mundo sem fome e doenças, chegando a defender alguns cientistas que aqueles que militavam e suspeitavam da possibilidade de nocividade, eram pesquisadores imbuídos de medos e que não se atentavam para os reais perigos, que era o empobrecimento da nação. (BOUGUERRA, 1997)

Da mesma forma eram considerados os efeitos radioativos, chegando a ser afirmado pelo Prêmio Nobel de química do ano de 1960, que o mundo sendo radioativo, uma pequena exposição proveniente de bombas atômicas não seria perigosa. (BOUGUERRA, 1997)

Mais um exemplo do que era defendido pelos cientistas e pelas organizações envolvidas era a discussão acerca do tabaco, cujo posicionamento majoritário era no sentido de não ser possível sua vinculação como causa/consequência de câncer, visto que esta patologia pode ser decorrente de diversas influencias.

Sobreleve-se que, atualmente é conhecido os efeitos nocivos, persistentes e demasiado preocupantes destas poluições, tanto dos produtos químicos, quanto da nuclear. Todavia, muitas outras formas de poluição invisíveis são desconsideradas sob a justificativa 
de que não se estabeleceu relação de causa e efeito, ou não se comprovou cientificamente o malefício, ou ainda que não se conhece totalmente os efeitos da tecnologia produzida.

Neste sentido, a poluição eletromagnética, e até mesmo os transgênicos podem ser enquadrados, o que permite o questionamento de que tais tecnologias são inofensivas como anteriormente foi defendida como segura a atividade nuclear.

E atualmente, de alguma forma, posiciona-se sobre elas, "são já muitos os setores em que se decide na incerteza e em meio a controvérsia científica; para mencionar dois deles como exemplo, podemos referir as ondas electromagnéticas ou os organismos geneticamente modificados". (PARDO, 2015, p. 39)

O problema dessas poluições é que não a vemos, ela passa desapercebida no cotidiano da coletividade. Imagine-se a quantidade de substância química consumidas no mundo. Imagine-se, de que muitas dessas substâncias são descartadas no esgoto, consequentemente alcançadas nos rios e mares. Lá, num mesmo ambiente, podem se juntar e formar novas substâncias, nocivas ou não ao meio ambiente e a saúde.

Da mesma forma, é acerca dos agrotóxicos, cujos alimentos misturados nas bancas dos supermercados restam impossíveis de dizer quais e quanto de resíduos de agrotóxicos estão presentes nos alimentos.

Os transgênicos também estão inseridos nesta poluição que não se vê, quando se observa que modificando formas de vidas e alterando artificialmente os genes para produzir plantas e animais, os resultados desses trabalhos é uma possível poluição genética.

É sabido que qualquer modificação ambiental pode gerar um efeito dominó com mudanças que afetam todo o ecossistema.

A ciência de hoje é tão subvertida que trabalha com a preocupação de indicar um padrão, um índice de ingestão diária aceitável, o que nada mais é do que permitir um envenenamento gradativo.

O que dizer do efeito cumulativo das poluições, o organismo humano é bombardeado por diversos produtos químicos vindos do ar, da água e da terra, porque não dos alimentos consumidos, e ainda as emissões magnéticas, elétricas e eletromagnéticas e mais, o desconhecimento de longo prazo para a saúde e para o meio ambiente.

Para o entendimento dessas interações das condições naturais é necessário ter uma visão geral, na qual o homem passa a ser um integrante da natureza, como todos os demais.

E estas interações negativas com a natureza atingem a saúde do homem, em virtude da emergência de epidemias, doenças causadas pela poluição, pelos agentes químicos e, em 
destaque, as possíveis doenças causadas pelo avanço tecnológico, no qual a ciência não é ainda capaz de se posicionar sobre sua nocividade ou não.

Desde o aparecimento do ser humano no globo terrestre, o homem vem interferindo no seu meio ambiente, promovendo grandes alterações em virtude do desenvolvimento tecnológico que vem experimentando, principalmente, desde a Revolução Industrial, momento este da explosão desenvolvimentista.

Todavia, esta exploração exacerbada dos recursos naturais proporcionou um desequilíbrio nos processos ecológicos, nos ecossistemas, que não trouxe apenas o desrespeito pelas demais formas de vidas, mas também para o próprio homem, que tem sofrido com os seus efeitos.

Assim, criou-se um panorama para o desastre ecológico, não só apenas dos desastres naturais, mas também da crescente exclusão social, ausência de proteção das minorias, antagonismos, doenças seja física ou psicológica.

Neste sentido, bem próximo da discussão acerca da degradação ambiental está a saúde, pois desde os primórdios ela está relacionada com provisão de água em quantidade e qualidade, como também a disposição dos resíduos, visto que é um dos principais criadouros de vetores, e ainda o desmatamento e a poluição do ar e do solo.

Segundo a Organização Mundial de Saúde, o conceito de saúde perpassa o bem-estar físico, mental, social, ou seja, não é apenas a inexistência de doença. Saúde é um equilíbrio dinâmico. É o equilíbrio do homem e do meio ambiente, suas interações equilibradas e, deve ser vista como um contexto de múltiplos fatores, influências e interesses, de modo a ser realizada em diversos setores, tendo como a proteção do meio ambiente e dos recursos naturais uma ocupação primordial na promoção da saúde. (IANNI; QUITÉRIO, 2006)

Assim, do mesmo modo que o meio ambiente necessita da transdisciplinaridade e da visão complexa do pensamento, assim também é a promoção da saúde, que se afasta um pouco do sistema vigente centrado na doença e no hospital, para focar nas doenças relacionadas ao estilo de vida e meio ambiente, justificando um novo olhar das práticas curativas e preventivas.

Remonta-se a saúde no inicio do séc. V a.C. na Grécia, nos estudos da escola Hipocrática, que já reconhecia a influência do local no desenvolvimento de doenças, ou seja, afirmavam que as diferentes condições geográficas resultavam em diferentes padrões de doenças, destacando o clima, a vegetação e a hidrografia. Ora, vislumbra-se o início da reflexão do papel do meio ambiente nas condições de saúde a que a população estava inserida. 
As obras de Hipócrates e seus seguidores foram a base para epidemiologia, higienismo e os movimentos sanitaristas, que colocam o meio ambiente como a base para a identificação da origem e a solução dos problemas de saúde. (RIBEIRO, 2004)

Nos séc. XVI até meados do séc. XVIII ocorre um período de transição, apesar de ser restrita a continuidade do inter-relacionamento entre a saúde e ambiente, apoderou-se do crescimento do conhecimento científico, com importantes estudos, como a classificação das doenças, a ideia de que organismos microscópios poderiam causar doenças transmissíveis, como também se dá importância aos movimentos políticos de reivindicação de melhores condições de saúde para os menos favorecidos.

Corroborando com este avanço, observa-se que o séc. XIX foi também o de grande desenvolvimento da ecologia e disciplinas a fins como área de estudo, sendo desenvolvido o conceito de ecossistemas e o estudo integrado dos organismos.

Todavia, neste período a metodologia aplicada era o controle dos vetores por meio de sua destruição e para tanto, utilizava-se, principalmente, pesticidas como o DDT (DicloroDifenil-Tricloroetano) conciliados a supressão do biótopo. ${ }^{1}$ Consequentemente, ocorreu a resistência dos organismos as substâncias utilizadas para seu controle, gerando efeitos negativos não esperados, como a contaminação de pessoas e, principalmente, do meio ambiente, como o solo e a água.

Desde estas primeiras observações de interações já era possível identificar a necessidade que o modelo de saúde ambiental fosse repensado frente às contaminações e poluentes, focando nos aspectos da prevenção, momento pelo qual a questão ambiental desenvolveu-se no sentido de demonstrar a necessidade de mudança de paradigma.

Entretanto, atualmente deve-se estudar e discutir as tecnologias que aparentemente não demandam perigo para a sociedade, visto que a pesquisa científica é dinâmica e incerta, o que hoje é considerado seguro, amanhã se torna nocivo, como no caso das pesquisas e utilização do citado DDT.

Além disso, deve-se ater a seguinte pergunta: e a Ciência? Atua em nome de quem? Isso porque sabemos que para a realização de estudos científicos existe o patrocínio e financiamento privado, cujos interesses podem influenciar no direcionamento dos resultados da pesquisa.

\footnotetext{
${ }^{1}$ Biótopo pode ser considerado como uma área geográfica de superfície e volume variáveis, submetida a características ambientais homogêneas, e capaz de oferecer as condições mínimas para o desenvolvimento de uma comunidade biológica a ele associada.
} 
Aqui reside o papel da bioética e do biodireito relacionado a quebra do paradigma cientificista e da visão desenvolvimentista e capitalista. O pensamento complexo e transdisciplinaridade leva a uma melhor avaliação do risco inserido no contexto social e ecológico.

Por isso, sugere-se que

\begin{abstract}
A biossegurança somente é possível com um compromisso ético dos cientistas, enfim, de todos. Por quê? Porque a ciência está a serviço do poder econômico. Não é à-toa que a indústria farmacêutica é a que mais fatura no mundo, ao lado da indústria bélica. (LEITE; FAGÚNDEZ, 2008, p. 290)
\end{abstract}

Em concomitância, as pesquisas científicas devem ser acompanhadas das avaliações de riscos, ressaltando, realizadas de forma coerente e ética, para que a sociedade moderna não sofra futuramente com riscos inimagináveis.

E diante da presença dos riscos, restará a ser perguntado: é possível optar e anuir com os riscos a que a população está sujeita? Para que se possa avaliar com mais clareza os efeitos dessas novas tecnologias, deve-se atentar para a visão sistêmica, holística e complexa dos temas e suas sobreposições, considerando a relação entre os mais diversos aspectos.

Deve-se ter uma visão da saúde em sua complexidade, onde o ser humano é um ser multidimensional, corpo, espírito, mente, afastando a visão mecanicista de mundo e o olhar tradicional. (LEITE; FAGÚNDEZ, 2008)

\title{
3. O BIODIREITO E A COMPLEXIDADE: UM BREVE OLHAR
}

Há muito tempo a ciência produz conhecimento para gerar lucro, associando seus objetivos aos interesses econômicos imediatos. Não deve gerar espanto algum afirmar que o relacionamento da ciência e do desenvolvimento é congênito, da mesma forma a relação intima da ciência com a indústria. (ALVARES, 2000, p. 44)

Essa influência privada é abordada por José Esteve Pardo (2015, p. 104) quando afirma que "o conhecimento está deixando de ser um bem aberto ao interesse geral, acessível sem reservas aos poderes públicos, para se tornar uma mercadoria calculadamente produzida e apresentada em atenção a determinados interesses privados e comerciais”"

Não se pode afastar que a ciência moderna ampliou as possibilidades, modificou a realidade de modo positivo também, mas atualmente a sua maior contribuição está sendo 
vinculada a uma esfera negativa, tendo em vista a dissociação da ética onde se promove o conhecimento científico a qualquer preço.

Edgar Morin (2000, p. 16) afirma que a ciência apresenta um antagonismo, uma ciência boa e uma ciência má,

essa ciência elucidativa, enriquecedora, conquistadora e triunfante, apresenta-nos, cada vez mais, problemas graves que se referem ao conhecimento que produz, à ação que determina, à sociedade que transforma. Essa ciência libertadora traz, ao mesmo tempo, possibilidades terríveis de subjugação. Esse conhecimento vivo é o mesmo que produziu a ameaça do aniquilamento da humanidade.

O lado mau da ciência está relacionado com a superespecialização, o enclausuramento e fragmentação do saber; dá-se um desligamento das ciências naturais e da ciência dos homens; é um saber que deixa de ser pensado, meditado, refletido e discutido, destinando ao acumulo em bancos de dados para depois ser utilizado por instâncias manipuladoras. O autor Edgar Morin (2000) chega a cogitar até mesmo o que ele chama de neo-obscurantismo, quando o próprio especialista se torna ignorante de tudo o que não diz respeito a sua disciplina.

Esse pensamento simplista é

fruto da modernidade e da sociedade industrial, cujo conteúdo está na ideia construída pela razão. Aqui, existe uma concepção metafísica segundo a qual o sujeito é separado do objeto que é conhecido, sendo ambos vistos de forma isolada, influenciando a formação do pensamento científico clássico. (LEITE, 2015, p. 32)

O autor Paulo Roney Ávila Fagundez (2013, p. 105) destaca o prejuízo do pensamento fragmentado na ciência: "A ciência, assim, emprega o pensamento simples para a explicação dos fenômenos que são, naturalmente, multicausais".

O que se percebe, atualmente, é que muitas dessas tecnologias sofrem com a postura passiva da ciência em não se debruçar sobre os riscos dessas atividades, visto que esta permanece arraigada aos métodos científicos, ao método cartesiano, sem a orientação da crescente complexidade e interdependência dos temas atuais.

Além disso, fica estancada também na fundamentação de que não há justificativas para se adotar uma postura protetiva, bem como nas relações custo-benefícios e negociatas por interesses econômicos. (BOUGUERRA, 1997)

Desde a Conferência das Nações Unidas sobre o Meio Ambiente e o Desenvolvimento, a Rio-92, já se defende menos fetichismo da prova científica, mais princípio da precaução, 
onde solicita aos países que não esperem por certezas absolutas para tomar as medidas cabíveis a prevenir os danos ao meio ambiente. (BOUGUERRA, 1997)

Desta forma, o grande problema reside que

os poderes criados pela atividade científica escapam totalmente aos próprios cientistas. Esse poder, em migalhas no nível da investigação, encontra-se reconcentrado no nível dos poderes econômicos e políticos. De certo modo, os cientistas produzem um poder sobre o qual não têm poder, mas que enfatiza já todo-poderosas, capazes de utilizar completamente as possibilidades de manipulação e de destruição provenientes do próprio desenvolvimento da ciência. (MORIN, 2000, p. 18)

Por certo que a ciência opera com a seleção de dados significantes e a rejeição de dados não significantes, utilizam-se de uma lógica, formam paradigmas e verdades absolutas, operam no princípio da visão unidimencional simplista, onde o princípio da disjunção isolou três grandes campos do conhecimento: a física, a biologia e a ciência do homem. (MORIN,

2015)

Mas esse parcelamento do conhecimento hoje não pode prosperar frente a notoriedade da complexidade das questões atuais. Permanecendo neste paradigma, a ciência começou a não mais responder as perguntas e os problemas, o que tem produzido uma crise na confiança dos critérios, regras, instituições e produções científicas. A hipótese de influência dos patrocínios particulares da pesquisa científica também coloca dúvidas sobre a confiabilidade das informações e das instituições de pesquisa.

E essa visão negativa da ciência também alcançou o Direito, que se fragmentou, compartimentou-se sem voltar suas análises para a interação dos acontecimentos humanos. Mais do que essa influência, na modernidade o Direito também sofreu com o domínio da ciência, como afirma José Esteve Pardo. (2015)

A questão é que a verdade e a certeza estão inseridos no dogma da segurança jurídica, neste sentido ele explica que é um desafio para o jurista a construção de um Direito que saiba operar e decidir na incerteza, que saiba mover-se, isso porque tem-se um sistema jurídico construído justamente sob o paradigma contrário, o da certeza, da segurança jurídica. (PARDO, 2015)

Essa certeza, essa segurança jurídica é um elemento estrutural do sistema, mas que atualmente vem sendo pressionado pela expansão da incerteza trazida pela pós-modernidade, "a incerteza, a complexidade se geram e se expandem fora dos limites do Direito, mas acaba por fazer-lhe um estreito cerco, abrindo brechas e introduzindo-se nele", o que está afetando as estruturas e peças básicas do direito. (PARDO, 2015, p. 19) 
O que é preocupante nesta relação é que o Direito continua buscando certezas na ciência, embora o que obtém dela são, quando muito, probabilidades. E ainda mais preocupante é observar que

\begin{abstract}
se fecha um circulo que se inicia quando a ciência, com seus avanços, levanta incertezas que afetam a direitos e valores relevantes que ela não resolve; são as instancias políticas e jurídicas que hão de decidir; mas estas, por sua vez, remetemse à ciência na busca de certezas que ali com frequência não encontram, com o risco de que seja a tecnociência organizada que acabe ganhando espaços de decisão com o déficit de legitimidade resultante. (PARDO, 2015, p. 26)
\end{abstract}

Neste cenário, José Esteve Pardo (2015) alerta que a solução não está no Direito entregar suas decisões para o sistema da ciência, mas de construir seu próprio sistema de referências e suportes para decisões, sem o objetivo de acerto científico. Por certo que, o Direito não poderá aguardar até a ciência ter produzido pesquisas e dado resultados sobre algumas incertezas.

Todas estas decisões, tomadas em áreas de incerteza abertas pelo desenvolvimento tecnológico, tem vigor e conflituosidade jurídica - proteção, saúde, meio ambiente, interesses econômicos, sociais.

E esta insegurança é a base para o novo pensamento, o qual deve ser guiado pela transdisciplinaridade como defende José Rubens Morato Leite (2004, p. 101), de que

a deficiência, a insuficiência, e/ou a inexistência de bases informativas seguras para a gestão dos riscos das sociedades contemporâneas são responsáveis pela modificação da qualidade do conhecimento que fundamentam a decisão, desvinculando-se de uma estreita dependência científica e do conhecimento disciplinar, para ganhar feições plurais, que relaciona os saberes de forma transdisciplinar, buscando atingir, através de uma postura dialógica, o conhecimento necessário para as decisões sobre os riscos, mas que ainda é indisponível.

A questão ambiental adotou o panorama da imprevisibilidade, onde não há controle sobre os processos, nem ao menos exercido pela ciência, e a sociedade contemporânea estabeleceu um ritmo tão acelerado de desenvolvimento e exploração dos recursos ambientais que acabou gerando cada vez mais situações de riscos.

Com a evolução industrial e o desenvolvimento da ciência e da tecnologia os riscos podem ser enquadrados como uma característica pertencente a esta sociedade, pois desde a sociedade industrial há a preponderância das incertezas científicas.

A sociedade de risco é aquela advinda da modernidade, onde começam a se manifestar os efeitos do modelo econômico da sociedade industrial. Ainda, é aquela que em virtude de seu 
contínuo crescimento econômico, pode ser acometida a qualquer tempo pelas consequências de uma catástrofe ambiental, ao mesmo tempo, é a sociedade que tem possibilitado a tomada de consciência do esgotamento do bem ambiental. (LEITE, 2013)

Esta sociedade promove uma condução equivocada do desenvolvimento, economia e da tecnologia, pois no seu modo de produção os recursos naturais são utilizados sem considerar seu valor intrínseco, além do mais, a ciência e a tecnologia encontram-se defasada para a proteção do bem natural e para garantir a segurança da coletividade.

O desenvolvimento da ciência e da tecnologia não conseguem mais predizer e nem controlar os riscos, estes de consequências incalculáveis para a saúde humana e para o meio ambiente e, na maioria, das vezes irreversíveis.

Ao seu turno, nem a bioética, nem o biodireito, ambos nas suas construções teóricas, institucionais e normativas, tem conseguido abordar as mais diversas poluições invisíveis em uma esfera protetiva da saúde do homem e das demais vidas.

A bioética "na condição de ética aplicada de cunho prescritivo, voltada para a solução de conflitos concretos em contextos variados, há de se ocupar das consequências decorrentes do encontro entre culturas distintas no campo da medicina, das ciências da vida e das tecnologias". (ALBUQUERQUE, 2015, p. 81)

A bioética se preocupa com o destino da humanidade, faz analises a partir de valores éticos e fatos biológicos.

A ética é mecanismo necessário para imprimir responsabilidade aos indivíduos, e não apenas a noção de dever, como impõe o Direito. Neste sentido, é importante observar os diversos sentidos da ética, desde a minha relação comigo mesmo (éthos), como também a minha relação com o outro, onde me coloco no lugar do outro (ethos) e também como sendo o conjunto de tradições e valores passados de uma geração a outra (mores). (FAGÚNDEZ, 2005)

Ela é "a teoria ou ciência do comportamento moral dos homens em sociedade, [...] a ciência de uma forma específica de comportamento humano”. (VÁZQUEZ, 2000, p. 23)

Logo, a ética é um complexo instrumento de análise própria e também social, onde não basta apenas a observância normativa, faz-se essencial atitude e responsabilidade.

Por isso, a crença de que a ética é o reencontro com o que é justo, no sentido de que sem valores, atitudes e responsabilidades o Direito não será capaz de oferecer amparo aos conflitos cotidianos. 
O que se deve pensar é a ética, a ciência, o ambiente e o bom uso das certezas e incertezas cientificas.

A visão compartimentada, a mudança de paradigma para uma visão mais sistêmica,

o direito vem produzindo a crise ecológica, à medida em que sanciona condutas e cria tolerâncias, porquanto compactua com o denominado progresso da civilização. Em verdade, os operadores não apenas resolvem problemas. Em certas situações, criam outros mais graves. A questão fulcral é que no sistema somente operamos com categorias licito e ilícito. (...) A inclusão da conduta ilícita no campo do lícito pode provocar uma tolerância insustentável, sendo causa do ecocídio. Ademais, o grande problema reside na fragmentação, porque se considera a questão ambiental como algo isolado dentro do contexto jurídico. (FAGÚNDEZ, 2005, p. 584)

As relações humanas, seja entre os homens, animais ou com a vida deve ser pensada sob o prisma da sensibilidade, existindo a necessidade de se estabelecer um direito da bioética, um direito preocupado com a vida nas suas mais diversas formas.

A crise é o ambiente propício para fomentar um debate a respeito da necessária mudança de paradigmas, abandonando os conceitos de verdade, racionalidade, ciência como valores absolutos, aproximando a ética das relações e dos saberes.

Como bem ensina Paulo Roney de Ávila Fagundez (2013, p. 115), "não se pode ver a vida dividida. A vida é uma totalidade. Nela todos os seres estão inseridos, com suas alegrias e tristezas, sonhos e sofrimentos. E a vida é a expressão maior de tudo. Há uma vida que é total e que transcende a pobre percepção que temos dela".

Por isso, o olhar para o pensamento complexo trará substratos para o enfrentamento dos desequilíbrios trazidos pela atividade humana, "não se trata de simplesmente de descobrir o que ainda nem foi construído, porém de proporcionar uma visão sistêmica e complexa do bem ambiental." (LEITE, 2015, p. 32)

E o que é o pensamento complexo? Edgar Morin (2015, p. 13) responde acerca da complexidade,

é um tecido (complexus: o que é tecido junto) de constituintes heterogêneas inseparavelmente associadas: ela coloca o paradoxo do uno e do múltiplo. Num segundo momento, a complexidade é efetivamente o tecido de acontecimentos, ações, interações, retroações, determinações, acasos, que constituem nosso mundo fenomênico. Mas então a complexidade se apresenta com os traços inquietantes do emaranhado, do inextricável, da desordem, da ambiguidade, da incerteza...

E continua, "a dificuldade do pensamento complexo é que ele deve enfrentar o emaranhado (o jogo infinito das inter-relações), a solidariedade dos fenômenos entre eles, a bruma, a incerteza, a contradição". (MORIN, 2015, p. 14) 
Pensar complexo, portanto, é abandonar o pensamento linear fundamentado no paradigma moderno e nas certezas científicas, passando a entender o mundo sob uma visão global, não uniforme e líquido; é perceber que o pensamento científico deve estar sempre acessível a novas perspectivas”. (LEITE, 2015, p. 39)

Não há mais como compartimentar os problemas e as indagações, a ciência pósmoderna deve-se pautar em uma racionalidade complexa, o que também deve pautar a atual orientação e atuação do Direito. "[...] são oportunos (o pensamento complexo) para a epistemologia ambiental e, apesar de pouco estudada a aplicação de sua teoria no Direito, visualiza-se que o Direito Ambiental é um gancho de transferência exatamente por possuir toda uma lógica diferenciada.” (LEITE, 2015, p. 35)

Questiona-se: “A modernidade necessita ver o sujeito massacrado pela globalização e pelo consumismo exacerbado. Qual a causa do mal-estar generalizado? Para onde estamos caminhando?" (FAGUNDEZ, 2008, p. 292)

O cenário é preocupante, como bem demonstra José Rubens Morato Leite (2000, p. 13):

\begin{abstract}
A primeira e imediata resposta seria que é muito difícil esta tarefa face á complexidade dos problemas emergentes e à situação de transição que enfrenta a sociedade, através da globalização e de outros fenômenos emergentes. É evidente o esvaziamento da capacidade regulatória do Estado tendo em vista os novos fenômenos de dimensão global e intensificação da pressão exercida por entidades não-governamentais de alcance transnacional.
\end{abstract}

Mas uma possível resposta de superação ensina Paulo Roney Ávila Fagúndez (2004, p. 557), que

\begin{abstract}
a questão ambiental é transcendental, porquanto leva à mudança na ciência política tradicional e contribui para que se promova uma ruptura na maneira tradicional de se ver o homem no universo. Não se trata apenas de ter uma visão preservacionista, mas de assumir uma postura que permita promover uma nova e ampla visão da vida, nas suas múltiplas manifestações.
\end{abstract}

Assim como tivemos religiões monoteístas anti-ecológicas, também estabelecemos um modelo científico contrário ao meio ambiente.

Precisamos de um saber ecológico e de uma ciência sustentável.

A busca pela vida, pela dignidade do homem e das demais formas de vida, a sobrevivência do planeta, não se fará em uma busca isolada, busca individual de cada cientista, por meio de um conhecimento fragmentado. (DANSEREAU, 1999)

Mas pela conjugação da ciência, do biodireito, da bioética, dos seus princípios e valores, da busca pela proteção ambiental, todos analisados sob o viés da complexidade, analisados e inseridos no contexto social e atual. 


\section{CONSIDERAÇÕES FINAIS}

O cenário atual impõe muitos desafios e questionamentos, como a possibilidade de proteção dos direitos fundamentais à vida, à saúde e à dignidade do homem e do Planeta com o atual modelo de econômica, sociedade, consumo e produção de conhecimento.

É latente a prejudicialidade do modelo econômico capitalista que subjulga o homem e todas as demais formas de vida ao sistema de objeto e mercadoria.

E neste sentido, com a subjugação da natureza e com a valoração demasiada do capital, o desenvolvimento pautado no poder econômico refreou os demais direitos do homem, como a dignidade da pessoa humana principalmente das camadas sociais mais baixas, onde reside o desrespeito de quaisquer direitos dos homens quando colocado em conflito com o desenvolvimento e com a economia. O que se vislumbra é que o poder econômico sempre vence a batalha e, com isso, os homens e o meio ambiente permanecem desprotegidos.

O problema não está somente na elaboração normativa e na judicialização dos conflitos, mas nos valores éticos e morais da sociedade pós-moderna, onde o individualismo é a regência das relações pessoais.

O panorama social e ambiental atual não permite a abstenção da confecção de novos pensamentos, a fim de salvaguardar todos os seres, a existência humana e a qualidade de vida.

Assim, é obrigação social a tentativa de calcar esforços na elaboração de diretrizes para uma repaginação efetiva do direito, como também uma transmutação da sociedade e de seu atual estilo de vida.

Neste sentido, as ciências não podem tornar teorias absolutas, sendo certo que sua finalidade é a avaliação das diversas teses pela busca do que é melhor e mais adequado. E é claro, que neste processo de decisão tomar-se-á a escolha com base nos discursos e na transdisciplinaridade dos saberes.

Especificamente com relação as diversas formas de poluição invisível é essencial a utilização da transdisciplinaridade a fim de que o panorama complexo possa se tornas mais claro e evidente. A dificuldade aqui reside de que estas poluições não são fáceis de serem constatadas, o que demanda ainda mais um novo olhar visto a partir do pensamento complexo, frente aos novos riscos neste mundo de incertezas. 
O sonho de uma civilização melhor é difícil de se realizar, é um sonho de afastar toda a forma de exploração e dominação, sendo um processo onde exista a cooperação e compreensão em todos os aspectos da vida, nos conhecimento e nas condutas humanas. Essa mudança de condutas e pensamentos, novas reflexões e novas teorias morais é essencial para um mundo de incertezas, com normas e valores problemáticos.

A ecologização do sistema jurídico é a medida necessária para se mudar a visão do mundo.

Ademais, há a necessidade de se adotar um saber sustentável.

Não se pode mudar a visão do mundo sem uma política alicerçada na ecologia, o que está intimamente ligada ao pensamento complexo, sistêmico e holístico.

\section{REFERÊNCIAS}

ALBUQUERQUE, Aline. Perspectiva bioética intercultural e direitos humanos. In Revista Bioética. Vol. 23, nº 1 - 2015. Brasília/DF, Brasil, Conselho Federal de Medicina, 2015.

ALBUQUERQUE, Letícia. Poluentes Orgânicos Persistentes: Uma análise da Convenção de Estocolmo. Curitiba: Juruá, 2006.

ALVARES, Claude. Ciência. In Wolfgang Sachs. Dicionário do Desenvolvimento. Tradução Vera Lucia M. Joscelyne, Susana de Gyalokay e Jaime A. Clasen. Petrópolis: Vozes, 2000. (1 ${ }^{\text {a }}$ ed. eletrônica)

BECK, Ulrich. Risk Society, 1999.

BOUGUERRA, Mohamed Larbi. A Poluição Invisível. Tradução de Luíz Paulino Leitão. Lisboa: Instituto Piaget, 1997.

BROWN, Lester. Building a sustainable society, Norton, Nova York, 1981. In: CAPRA, Fritjof. As conexões ocultas: ciência para uma vida sustentável. São Paulo: Cultrix, 2005.

CAPRA, Fritjof. As conexões ocultas: ciência para uma vida sustentável. Tradução Marcelo Brandão Cipolla. São Paulo: Cultrix, 2005.

CAPRA, Fritjof. O Ponto de Mutação. São Paulo: Cultrix, 1982.

DANSEREAU, Pierre. Ecologia Humana, ética e educação. Pallotti/Aped, 1999.

FAGUNDEZ, Paulo Roney Ávila. Direito, transdisciplinaridade e a hipercomplexidade. Interparadigmas: a revista de doutores da Conscienciologia, v. 1, p. 103-116, 2013. 
FAGÚNDEZ, Paulo Roney Ávila. Os direitos humanos e a sociedade globalizada: a necessidade de se ir além da política. Revista Seqüência, nº 50, p. 169-187, jul. 2005.

FAGÚNDEZ, Paulo Roney Ávila. Reflexões sobre o Direito Ambiental. In: Leite, José Rubens Morato e (org.). Direito Ambiental Contemporâneo. São Paulo: Manole, 2004.

GUATTARI, Félix. As três ecologias. Tradução Maria Cristina F. Bittencourt. Campinas: Papirus, 1990.

IANNI, Aurea Maria Zöllner; QUITÉRIO, Luiz Antonio Dias. A questão ambiental urbana no programa de saúde da família: avaliação da estratégia ambiental numa política pública de saúde. Ambiente \& Sociedade. vol. IX nº. 1 jan./jun. 2006.

LEFF, Henrique. Conferência "La esperanza de un futuro sustentable: utopía de la Educación Ambiental". VI do Congresso Iberoamericano de Educação Ambiental. Disponível em: <http://www.youtube.com/watch?v=4z6_DekehPI>. Acesso em 01 abr 2016.

LEFF, Henrique. Epistemologia ambiental. Tradução de Sandra Valenzuela. São Paulo: Cortez, 2001.

LEITE, José Rubens Morato; AYALA, Patrick de Araújo. Transdisciplinariedade e a Proteção Jurídico-ambiental em sociedade de Risco: Direito, Ciência e Participação. In: Leite, José Rubens Morato e (org.). Direito Ambiental Contemporâneo. São Paulo: Manole, 2004.

LEITE, José Rubens Morato, et. al. Sociedade de risco, danos ambientais extrapatrimoniais e jurisprudência brasileira. Disponível em:

<http://www.estig.ipbeja.pt/ ac_direito/direito_ambiental_jose_r_morato_leite_e_outros.pdf> . Acesso em: 01 abr. 2016.

LEITE, José Rubens Morato. Inovações em Direito Ambiental. Florianópolis: Fundação Boiteux, 2000.

LEITE, José Rubens Morato; FAGÚNDEZ, Paulo Roney Ávila. (Org.) Aspectos destacados da Lei de Biossegurança na Sociedade de Risco. Conceito Editorial: Florianópolis, 2008.

MORIN, Edgar. Ciência com consciência. Tradução Maria D. Alexandre e Maria Alice Sampaio Dória, ed. revista e modificada pelo autor, $4^{\mathrm{a}}$ ed. Rio de Janeiro: Bertrand Brasil, 2000.

MORIN, Edgar; KERN, Anne Brigitte. Terra-Pátria. Tradução Paulo Azevedo Neves da Silva, $2^{\mathrm{a}}$ ed. Porto Alegre: Saulina, 1995.

PARDO. José Esteve. O desconcerto do leviatã: política e direito perante as incertezas da ciência. Tradução Flávia França Dinnebier; Giorgia Sena Martins. São Paulo: Instituto O Direito por um Planeta Verde, 2015 (Série Direito Ambiental para o século XXI. Volume 3. Coordenador José Rubens Morato Leite).

RIBEIRO, Helena. Saúde Pública e Meio Ambiente: evolução do conhecimento e da prática, alguns aspectos éticos. Saúde e Sociedade v.13, n.1, jan-abr 2004. 
RIOS, André Rangel. Bioética no Brasil. Rio de Janeiro: Espaço e tempo, 1999.

SACHS, Wolfgang. Dicionário do Desenvolvimento. Tradução Vera Lucia M. Joscelyne, Susana de Gyalokay e Jaime A. Clasen. Petrópolis: Vozes, 2000. (1 ${ }^{\text {a }}$ ed. eletrônica).

VÁZQUEZ, Adolfo Sánchez. Ética. Tradução de João Dell’ Anna. 20ª ed. Rio de Janeiro: Civilização Brasileira, 2000. 